\title{
CFD NUMERICAL AND EXPERIMENTAL INVESTIGATION OF TWO-PHASE FLOW DEVELOPMENT AFTER AN EXPANSION DEVICE IN A HORIZONTAL PIPE
}

\author{
Raid Ahmed Mahmood ${ }^{1,2^{*}}$, David Buttsworth ${ }^{1}$, Ray Malpress $^{1}$, Ahmad Sharifian-Barforoush $^{1}$
}

\begin{abstract}
To optimize a vertical flash tank separator, the characteristics of the flow entering the separator are required to be known. A flash tank separator improves the performance of a refrigeration cycle by separating the liquid from liquid-gas flow and providing the evaporator with only liquid refrigerant. This technique improves the effective area and enhances the heat transfer coefficient in the evaporator. This paper investigates the influence of the inlet operating conditions to an expansion device, on the adiabatic two-phase flow development in a horizontal pipe downstream from the expansion device. This work also compares three dimensional numerical simulations and experimental observations for the two-phase flow development after the expansion device in the horizontal pipe. A general trend of the two-phase flow after the expansion device was gradually developed and the expansion length was identified at less than $200 \mathrm{~mm}$ from the inlet. The two-phase flow behaviour was recorded using a digital camera recording the flow behaviour at the upstream and downstream of the horizontal tube. The results revealed that an increase of the mass flow rate causes an increase in the void fraction and a reduction in the slip ratio in the developed region. The simulations underestimate the expansion length and the mean difference between the experimental data and the numerical results is $8 \%$.
\end{abstract}

Keywords: Two-Phase Flow, CFD Simulation, Expansion Region, Flow Patterns, Adiabatic Expansion, Two-phase Flow Development, Stratified Two-Phase Flow

\section{INTRODUCTION}

Two-phase liquid-gas flow is involved in various processes including air conditioning systems refrigerators and the petroleum industry [1]. In refrigeration and air conditioning systems, two-phase flow patterns play a significant role in distributing refrigerant in headers and/or flash tanks where effective refrigerant distribution improves the heat transfer characteristic of the evaporators [2, 3]. Flow classifications and two-phase flow development at the inlet of a flash tank separator influence the performance of the separator which consequently improves the refrigerant effect of the evaporator. There are many publications dealing with twophase flow characteristic in a horizontal tube; Awwad, Xin [4], Canière, T'Joen [5], Bhramara, Rao [6], Dalkilic, Agra [7], Ekambara, Sanders [8], Kondou and Hrnjak [9], Dasari, Desamala [10],Chen, Xu [2], Becker, Kapitz [11], Bottin, Berlandis [12], Rana, Agrawal [13], Duan, Gong [14]. However, few studies were reported for twophase flow development after an expansion device. For instance, Duan, Gong [14] investigated the effect of the two-phase flow on the refrigerant distribution in the evaporator and/or in the flash tank separator of the vapour injection system. Duan, Gong [14] reported that in two-phase flows there are various flow patterns such as stratified, slug, annular and dispersed flows, for different fluid properties and flow conditions. Tong [15] used flow type descriptors such as slug and annular in a numerical approach to predict two-phase flow behaviour of water-oil flow in gravity separators.

Shoukri [16] conducted experimental work to clarify the effect of the inlet flow conditions and junction geometry on phase redistribution and pressure drop in T-junctions under steam-water two-phase stratified flow condition. The experiment covered both horizontal and vertical downward flows under inlet steam and water superficial velocity range from 1.5 to $5 \mathrm{~m} / \mathrm{s}$ and 0.05 to $0.09 \mathrm{~m} / \mathrm{s}$ respectively. The study showed that phase

This paper was recommended for publication in revised form by Regional Editor Octavio Valladares

${ }^{1}$ School of Mechanical and Electrical Engineering, University of Southern Queensland, Australia

${ }^{2}$ Department of Mechanical Engineering, University of Zakho, Kurdistan Region, Iraq

*E-mail address: raidalnuaimi@yahoo.com

Orcid.id: 0000-0002-3237-9487, 0000-0003-2892-2296, 0000-0002-3810-3342

Manuscript Received 06 December 2018, Accepted 08 March 2019 
redistribution in the junction depends on the inlet flow regime, inlet phase velocities, fluid densities, junction geometry and branch mass flow split ratio.

Bowers [17] conducted experimental work to visualize the adiabatic two-phase flow developing in a horizontal tube after an expansion device in an R134a systems. The distance after the device was used to characterize phase separation. In the experiment, three tube diameters, $(7.2 \mathrm{~mm}, 8.7 \mathrm{~mm}$, and $15.3 \mathrm{~mm})$, were used with different ranges of mixture quality ( $1 \%$ to $30 \%)$ and range of mass flow rate (15 g/s to $40 \mathrm{~g} / \mathrm{s})$. At vapour quality $5 \%$ and $30 \mathrm{~g} / \mathrm{s}$ mass flow rate, the experimental results showed that at $180 \mathrm{~mm}$ from expansion device the two-phase flow pattern was stratified. Bottin, Berlandis [12] conducted an experimental study of adiabatic twophase flow in a horizontal pipe. Water and air were used as a two-phase working fluid. Flow pattern maps were recorded using High speed video. The results revealed that at a distance from the expansion device of 20 time the diameters of the pipe from the inlet of the pipe, the flow is separated into two zones: the lower region with very low gas void fraction and upper region with very high gas void fraction. Zhao, Chen [18] conducted an experimental study to evaluate the pressure effects on the hydrodynamic characteristic of gas-liquid two-phase flows in a T-junction micro channel. Nitrogen and de-ionized water were used as the working fluid to operate under a pressure range from 0.1 to $5 \mathrm{MPa}$. The gas weber number varied from $1.37 \times 10^{-5}$ to 3.46 under atmospheric pressure and from $1.70 \times 10^{-3}$ to 70.32 at elevated pressures. The results revealed that the operating pressure has significant effects on the two-phase flow behaviour.

From the open literature, the behaviour and flow pattern of the two-phase flow in a horizontal pipe at the developed region were presented and investigated. However, the expansion region length which is located directly after the expansion device in an adiabatic two-phase flow was not considered in the most previous studies. Most of the existing studies focused on the dispersed flow in small tubes using the modern refrigerants.

In the present study, numerical simulation and experimental investigations were conducted to investigate the two-phase flow development after the expansion device using water as the working fluid in a $25 \mathrm{~mm}$ inner diameter horizontal tube.

\section{MODEL DEVELOPMENT}

Figure 1 illustrates the geometry of a horizontal pipe connected to an expansion device considered for the present computational modelling. The pipe has an internal diameter and length of $25 \mathrm{~mm}$ and $2 \mathrm{~m}$, respectively. Liquid is supplied through the inlet as a single-phase flow. The expansion process initiates a well-mixed twophase flow with slip ratio of $1[17,19]$. This initial expansion region occupies a short distance directly after the expansion device [20]. The fluid then enters a non-stable developing stage where segregation starts under the effect of gravity [2]. After a certain distance, the flow starts maintaining stable volume fraction phases and enters the developed flow regime.

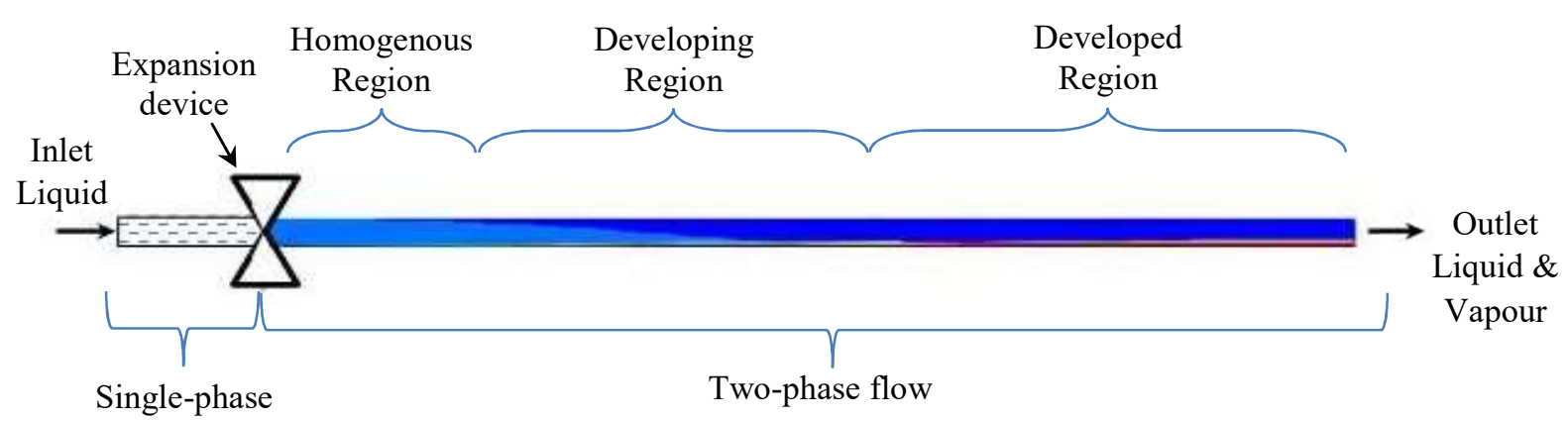

Figure 1. Schematic of pipe flow

\section{EXPERIMENTAL APPARATUS}

A schematic diagram of the facility used in the current study is presented in Figure 2 [29]. The experimental apparatus consists of the test section horizontal pipe, vacuum pump, condenser, heat exchanger and expansion device. Instrumentation, including video recording were used to measure the temperature, pressure and mass flow rate in the horizontal pipe. All the measurement transducers were connected to data acquisition. The test section horizontal pipe was $25 \mathrm{~mm}$ transparent acrylic tube. Simulation and trials of an experimental setup 
indicated that a length of $2 \mathrm{~m}$ would allow for steady flow conditions at the outlet of the test section for the range of operating conditions used. The camera was used in two positions: directly after the expansion device and at $1500 \mathrm{~mm}$ downstream from the inlet. Both positions have the same field of view, capturing $600 \mathrm{~mm}$ of the test section. Operating conditions covered the mass flow rate range from $2 \mathrm{~g} / \mathrm{s}$ to $23.4 \mathrm{~g} / \mathrm{s}$ with vapour quality in vicinity $5 \%$.

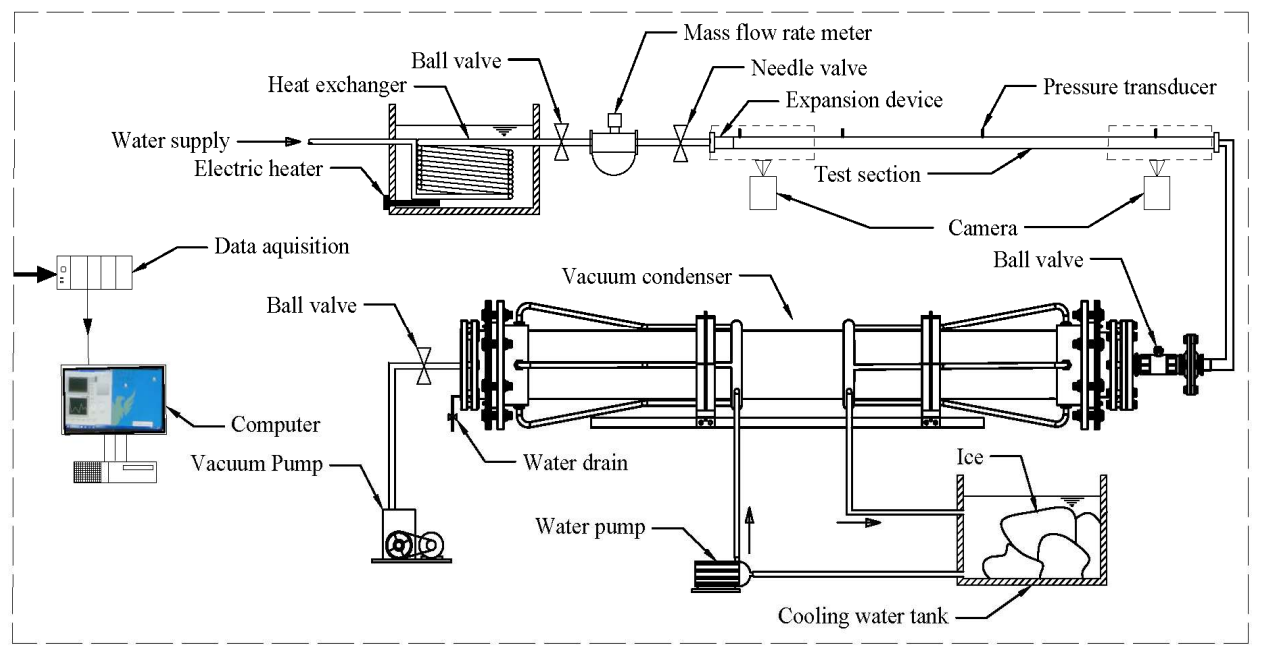

Figure 2. Schematic diagram of the expansion device and horizontal pipe experimental apparatus regimes

\section{ADIABATIC ENCLOSURE}

In order to obtain adiabatic operating conditions in the experiments, a cloth enclosure and heat gun were used to maintain the temperature of the walls of the test section at the water saturation temperature for the required operating pressure. The heat gun was a Hitachi model RH650V with LCD displaying the temperature and flow speed. By using the enclosure and the heat gun, the surfaces of the test sections were maintained relatively clear by preventing the condensation. In the horizontal tube experiments, the adiabatic enclosure was used at the upstream station while in the vertical flash tank separator experiments, the enclosure was used around the entire separator. Figure 3 presents the adiabatic enclosure arrangement in the experiments. The RTD sensors were used to measure the temperature around the walls of the test sections in both the horizontal pipe and vertical separator experiments. Because the laboratory temperature was lower than the saturation temperature by about $6{ }^{\circ} \mathrm{C}$ and it varied from day to day, the adiabatic enclosure was used. The temperature of the environment inside the enclosure was assumed to be same as the temperature of the surfaces of the test sections. The RTD sensors were located at different positions around the test sections and very close to the surfaces. As the saturation temperature depended on the required operating pressure, the saturation temperature range was varied with the operating condition but was between 20 and $23^{\circ} \mathrm{C}$, and the adiabatic enclosure temperature was varied accordingly.

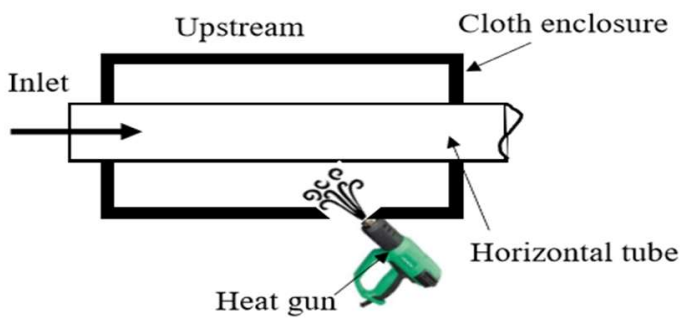

Figure 3. Adiabatic enclosure arrangement

\section{ANALYSIS OF EXPERIMENTAL UNCERTAINTY}

In the experiments, the systematic uncertainty of the measured parameters was considered according to the manufacture data of the instruments. Mass flow rate, pressure and temperature were directly measured in the experiments. All the measurement instruments were calibrated before running the experiments, the calibration test report of the instruments was provided by the manufacturers. Table 1 shows the designated uncertainty of the instruments based on manufacturers data. 
Table 1. Manufactures' designated uncertainty of the measurement instruments

\begin{tabular}{|c|c|c|c|}
\hline $\begin{array}{c}\text { Measured } \\
\text { parameters }\end{array}$ & Instrument type & $\begin{array}{c}\text { Operating } \\
\text { range }\end{array}$ & Uncertainty \\
\hline Pressure & Wika 10-A & $0-100 \mathrm{kPa}$ & $0.5 \mathrm{kPa}$ \\
\hline \multirow{2}{*}{ Temperature } & RTD (PT100) & $-50-+200{ }^{\circ} \mathrm{C}$ & $0.1^{\circ} \mathrm{C}$ \\
\cline { 2 - 4 } & Thermocouple (Type K) & $0-+200{ }^{\circ} \mathrm{C}$ & $0.75{ }^{\circ} \mathrm{C}$ \\
\hline Mass flow rate & Siemens & $\max 3700 \mathrm{~kg} / \mathrm{h}$ & $0.2 \mathrm{~g} / \mathrm{s}$ \\
\hline
\end{tabular}

The random errors arising in the experiments were identified by repeating the measurements several times to estimate the mean and the standard deviation $(\sigma)$ of the measured quantities. Uncertainties arising from the random errors are defined as $\mp 2 \sigma$ values and combined with the systematic uncertainties on the basis that the errors are statistically independent

\section{CFD TWO-PHASE FLOW MODELLING}

The CFD simulations were conducted by using ANSYS 17.1 FLUENT, which has three models options: Volume of fluid (VOF), Mixture model and Eulerian model. The most appropriate choice is influenced by the flow regime to be simulated, and four categories identified: gas-liquid or liquid-liquid flows, gas-solid flows, liquid-solid flows and three-phase flows [21]. In the gas-liquid flow regime, there are different flow patterns such as bubbly flow, droplet flow, slug flow, stratified wavy flow and stratified flow [22].

Many numerical simulations of gas-liquid two-phase flow have used the Eulerian model in different geometries including sudden expansion [23] and flow in a horizontal tube [24] because it has proven to be more accurate than the VOF and Mixture models [23]. In the Eulerian approach, the liquid phase and vapour phase are both treated as separate continuous phases determined by the volume fraction for each phase [25,32]. The Eulerian two-phase model solves a set of two-phase differential equations for each phase, so it is the most complex of the two-phase models [23]. Consequently, the computational effort required for the solution of the Eulerian model is higher than that in the VOF and Mixture models because the number of transport equations that need to be solved in Eulerian model is higher than that in VOF and Mixture models [30].

In the present work, as the flow regime is gas-liquid two-phase flow and the phases under throttling process effect in the expansion device which provides an adiabatic mixed well two-phase flow then these phases are being separated, the Eulerian model was used. The standard k- $\varepsilon$ turbulence model was used for each phase to represent the turbulence in the present work. The standard k- $\varepsilon$ turbulent model was selected according to the turbulent model compatibility with the multiphase model chart that is provided by FLUENT [25] as shown in Table 2 .

Table 2. the turbulence model compatibility with the multiphase model from FLUENT [25]

\begin{tabular}{|c|c|c|c|c|}
\hline Multiphase Models & k- $\boldsymbol{k}$ & k- $\boldsymbol{\omega}$ & Reynolds stress & LES \\
\hline Eulerian model & Yes & No & Yes & No \\
\hline VOF model & Yes & Yes & Yes & Yes \\
\hline Mixture model & Yes & Yes & Yes & No \\
\hline
\end{tabular}

The LES is the large eddy simulation turbulence model. In the present simulations, with little or no likelihood swirl flow, the Reynolds stress turbulence model was not used because it is typically only required to improve the simulation involving swirl flow by accounting for the effect of the streamline curvature and rapid change in strain rate in the rotational flow [25].

\section{GOVERNING EQUATIONS}

The governing equations solved by FLUENT 17.1 can be written according to the laws of continuity and conservation of momentum.

$$
\frac{\partial}{\partial t}\left(\alpha_{q} \rho_{q}\right)+\nabla \cdot\left(\alpha_{q} \rho_{q} v_{q}\right)=\sum_{p=1}^{n}\left(m_{p q}-m_{q p}\right)+S_{q}
$$




$$
\begin{aligned}
& \frac{\partial}{\partial t}\left(\alpha_{q} \rho_{q} v_{q}\right)+\nabla \cdot\left(\alpha_{q} \rho_{q} v_{q} v_{q}\right)=-\alpha_{q} \nabla p+\nabla \cdot \tau_{q}+\alpha_{q} \rho_{q} g+\sum_{p=1}^{n}\left(R_{p q}+m_{p q} v_{p q}-\right. \\
& \left.m_{q p} v_{q p}\right)+\left(F_{q}+F_{l i f t, q}+F_{v m, q}\right)
\end{aligned}
$$

In addition to the volume fraction for the individual phase which can be presented as follows

$$
V_{q}=\int \alpha_{q} d V
$$

Where

$$
\sum_{q=1}^{n} \alpha_{q}=1
$$

\section{TURBULENT MODEL}

The modelling of turbulence in multiphase flow is extremely complex compared to single phase, [26]. Kerdouss, Bannari [27] reported that the $k-\varepsilon$ model is appropriate for three-dimensional two-phase flow prediction because it employs transport equations that can be solved for $k_{q}$ and $\varepsilon_{q}$ which are kinetic energy and the dissipation rate for phase $q$ respectively. A model using $\mathrm{k}-\varepsilon$ for each phase is also appropriate when the turbulence transfer among the phases plays a dominant role. In the present study, Standard k- $\varepsilon$ turbulence model was applied. The k$\varepsilon$ equations are [25],

$$
\begin{aligned}
& \frac{\partial}{\partial t}\left(\alpha_{q} \rho_{q} k_{q}\right)+\nabla \cdot\left(\alpha_{q} \rho_{q} U_{q} k_{q}\right)=\nabla \cdot\left(\alpha_{q}\left(\mu_{q}+\frac{\mu_{t, q}}{\sigma_{k}}\right) \nabla k_{q}\right)+\left(\alpha_{q} G_{k, q}-\alpha_{q} \rho_{q} \varepsilon_{q}\right)+\sum_{p=1}^{N} K_{p q}\left(C_{p q} k_{p}-C_{q p} k_{q}\right)- \\
& \sum_{p=1}^{N} K_{p q}\left(U_{p}-U_{q}\right) \cdot \frac{\mu_{t, p},}{\alpha_{q} \sigma_{q}} \nabla \alpha_{p}+\sum_{p=1}^{N} K_{p q}\left(U_{p}-U_{q}\right) \cdot \frac{\mu_{t, p}}{\alpha_{q} \sigma_{q}} \nabla \alpha_{q} \\
& \frac{\partial}{\partial t}\left(\alpha_{q} \rho_{q} \varepsilon_{q}\right)+\nabla \cdot\left(\alpha_{q} \rho_{q} U_{q} k \varepsilon_{q}\right)=\nabla \cdot\left(\alpha_{q}\left(\mu_{q}+\frac{\mu_{t, q}}{\sigma_{k}}\right) \nabla \varepsilon_{q}\right)+\frac{\varepsilon_{q}}{k_{q}}\left[C_{1, \varepsilon} \alpha_{q} G_{k, q}-C_{2, \varepsilon} \alpha_{q} \rho_{q} \varepsilon_{q}+\right. \\
& \left.C_{3, \varepsilon}\left(\sum_{p=1}^{N} K_{p q}\left(C_{p, q} k_{p}-C_{q, p} k_{q}\right)\right)-\sum_{p=1}^{N} K_{p q}\left(U_{p}-U_{q}\right) \cdot \frac{\mu_{t, p}}{\alpha_{q} \sigma_{q}} \nabla \alpha_{p}+\sum_{p=1}^{N} K_{p q}\left(U_{p}-U_{q}\right) \cdot \frac{\mu_{t, q}}{\alpha_{q} \sigma_{q}} \nabla \alpha_{q}\right]
\end{aligned}
$$

\section{COMPUTATIONAL DOMAIN}

The domain of the horizontal tube under investigation is presented in Figure 4. The geometry was taken from the experimental configuration. In order to reduce the computational time, the domain represents half of the physical experiment with the symmetry applied along the vertical plane.

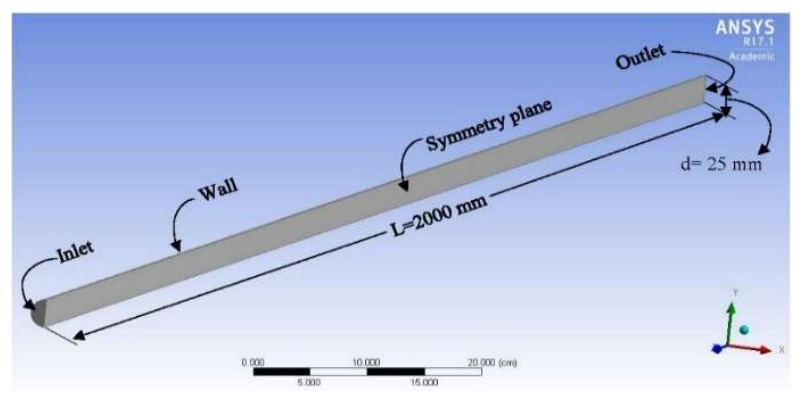

Figure 4. Computational domain of the horizontal tube

\section{BOUNDARY CONDITIONS}

Water was used as the working fluid. At the inlet, the liquid droplet size is selected according to the expansion device design which has 400 holes with $0.3 \mathrm{~mm}$ diameter, so the liquid droplet diameter is selected to be $300 \mu \mathrm{m}$. On the assumption that homogeneous flow is formed directly after the expansion device, the velocity at the inlet of the horizontal tube can be calculated based on the homogeneous void fraction [28]. The liquid velocity was calculated from

$$
u_{l}=\frac{m_{l}}{\rho_{l} A\left(1-\alpha_{g}\right)}
$$


Where the $\mathrm{A}$ is the total cross section area of the horizontal pipe, $\rho_{\mathrm{l}}$ is the liquid density, $\dot{m} l$ is the liquid mas flow rate and $\alpha_{\mathrm{g}}$ is the gas void fraction which can be calculated from;

$$
\alpha_{g}=\left[1+\left(\frac{1-x}{x}\right)\left(\frac{\rho_{g}}{\rho_{l}}\right)\right]^{-1}
$$

Similarly, the gas velocity at the inlet was calculated from;

$$
u_{g}=\frac{m_{g}}{\rho_{g} A \alpha_{g}}
$$

Where the $\rho_{\mathrm{g}}$ is the gas density, $\dot{m} g$ is the gas mass flow rate.

The inlet boundary condition was specified as uniform velocity distribution for each phase at the inlet of the horizontal tube. A pressure outlet was used for the outlet boundary condition. The no slip wall was applied for the wall boundary. Six cases were simulated for the same domain of the horizontal tube, each case corresponding to a particular mass flow rate that was used in the experiments [31]. Table 3 presents the boundary conditions which were used in the simulation in each case.

\begin{tabular}{|c|c|c|c|c|c|c|}
\hline Boundary & Case 1 & Case 2 & Case 3 & Case 4 & Case 5 & Case 6 \\
\hline \multirow{2}{*}{$\begin{array}{c}\text { Inlet (inlet } \\
\text { velocity, } \mathrm{m} / \mathrm{s} \text { ) }\end{array}$} & $u_{l}=0.33$ & $u_{l}=0.89$ & $u_{l}=1.37$ & $u_{l}=1.52$ & $u_{l}=1.91$ & $u_{l}=2.1$ \\
\hline & $u_{g}=0.33$ & $u_{g}=0.89$ & $u_{g}=1.37$ & $u_{g}=1.52$ & $u_{g}=1.91$ & $u_{g}=2.1$ \\
\hline $\begin{array}{c}\text { Outlet } \\
\text { (pressure } \\
\text { outlet, } \mathrm{kPa} \text { ) }\end{array}$ & 2.06 & 2.09 & 2.26 & 2.31 & 2.34 & 2.52 \\
\hline Wall & No slip & No slip & No slip & No slip & No slip & No slip \\
\hline
\end{tabular}

Table 3. Boundary conditions

\section{MESH INDEPENDENCE STUDY}

Five computational grids of 7000, 16232, 45000, 199356 and 298566 elements distributed within the domain were used to investigate appropriate grid size for computational simulation of the horizontal pipe case. The inflation method was used to generate a fine mesh near the walls. Figure 5 illustrates the mesh with mesh inflation near the wall of the horizontal tube. The operating condition case 6 presented in Table 3 was used in the simulations for the different element number meshes.

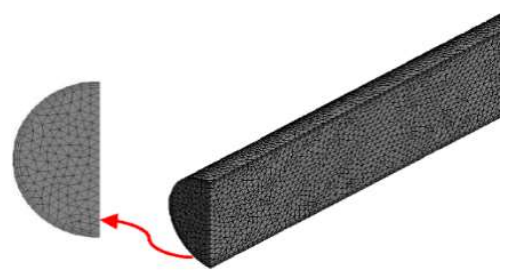

Figure 5. Horizontal tube mesh with inflation near the wall for the 199356 elements mesh case

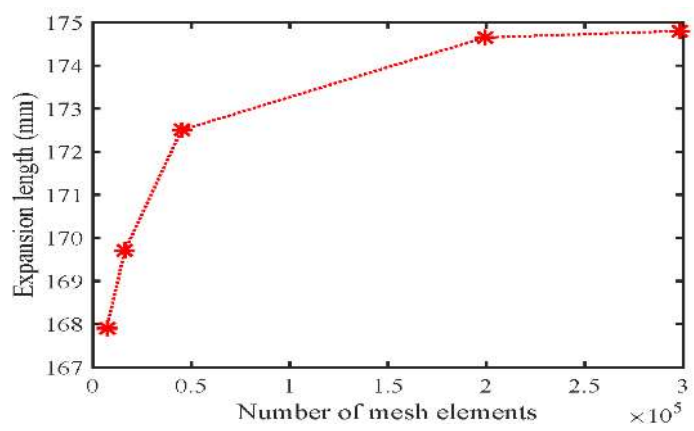

Figure 6. Assessment of grid independence for the horizontal tube showing variation of the expansion length with the number of mesh element for operating condition case 6 
As can be seen from the Figure 6, based on the calculation of expansion length, the simulations using the two highest number of mesh elements achieved convergence approximately the same length. The number of mesh elements selected for the primary simulations of the horizontal tube of the present work was 199356. Figure 7 shows the liquid volume fraction distribution in the horizontal pipe at $1600 \mathrm{~mm}$ from inlet of the tube for different mesh densities. The red area represents the liquid film at the bottom of the pipe and the transitional colors between the red and blue represents the interface between the phases. The figure illustrates the significant effect of the different element numbers on the resolution of the interface of two-phase flow. As can be seen there is no significant change in the liquid volume fraction and the smoothing of interface between the liquid and vapour when the mesh number increased beyond 199356.

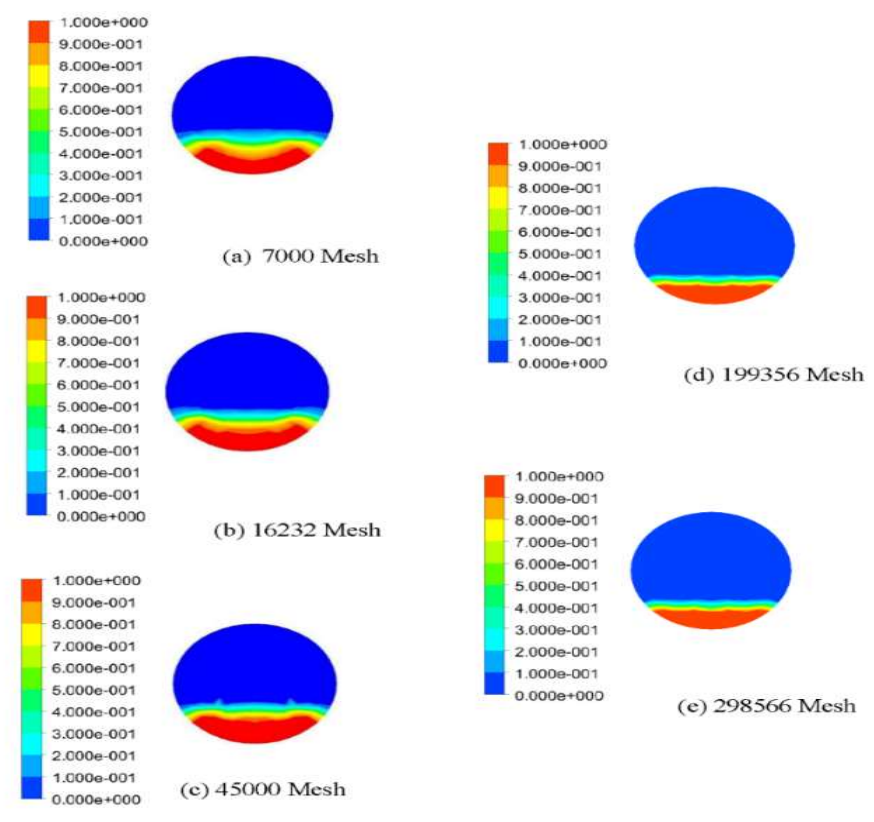

Figure 7. Assessment of grid independence showing liquid volume fraction contours for different element numbers in a horizontal pipe at $1600 \mathrm{~mm}$ from the inlet of the pipe for operating condition case 6

\section{RESULTS}

\section{Experimental Results}

Figure 8 shows a frame from video depicting the two-phase region, directly after the expansion device. This is from the experiment with $\dot{m}=13.1 \pm 0.2 \mathrm{~g} / \mathrm{s}$ with vapour quality of $5.4 \%$. This is consistent with description by Hrnjak [3], who reported that the liquid and vapour move together at a certain velocity directly after the expansion device where both phases are uniformly mixed (slip ratio is equal to one). Then, as the flow continues downstream, due to the effect of viscous and gravity forces, the phases are separated from each other resulting a reduction in liquid velocity [3]. When a significant amount of separation occurs, a distinctive feature is the liquid layer development at the bottom of the tube. The separation region is regarded as starting at the point where the liquid first appears in a continuous layer at the bottom of the tube. Downstream of this region, the flow is described as a stratified flow as the liquid has largely accumulated at the bottom while the vapour is moving on the top. Figure 9 illustrates a stratified flow pattern from the present experiments.

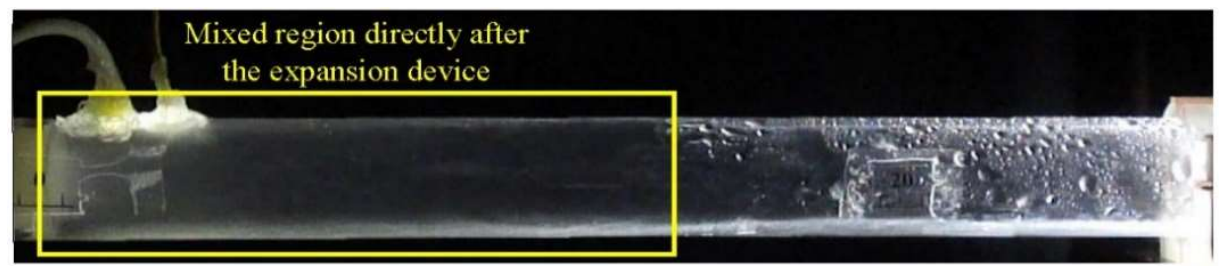

Figure 8. Homogenous flow (mixed flow) region of two-phase flow directly after the expansion device (flow direction from left to right) 


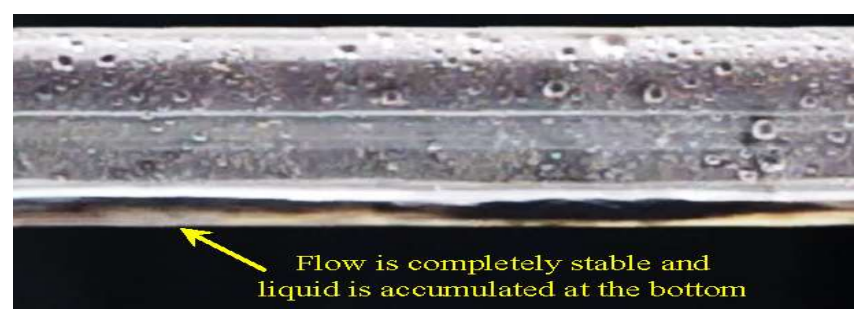

Figure 9. Stratified flow at $1600 \mathrm{~mm}$ from the inlet, $\dot{m}=10.2 \mathrm{~g} / \mathrm{s}$ and $\mathrm{x}=5.4 \%$ (flow direction from left to right)

As a result of the effect of shear forces from the interaction between phases and the tube wall and the no slip condition of the wall, the slip ratio grows [3]. In all operating conditions, liquid droplets are observed moving on the wall of the tube immediately after the expansion device, then they start to move towards the bottom of the tube as a result of liquid velocity reduction and the gravity effect. This adds to the droplets which fall out of suspended in the gas flow. Figure 10 presents the observed liquid droplet movement from the top to bottom of the pipe for liquid accumulating on the wall. A circle with an arrow highlights the liquid drop and its direction. According to observation in Figure 10, a sketch for liquid droplet trajectory is produced as shown in Figure 11 to illustrate the path of the liquid droplet during the movement from the top to the bottom of the pipe. Liquid droplets merging is observed in all the operating conditions. Figure 12 presents sequential frames illustrating liquid droplet merging at locations between $275 \mathrm{~mm}$ and $300 \mathrm{~mm}$ from the inlet for $\dot{m}=10.2 \mathrm{~g} / \mathrm{s}$ and x $=5.4 \%$. Images in Figure 13 and Figure 14 present the experimental observation of the two-phase flow directly after the expansion device and further downstream near the exit of the tube respectively.

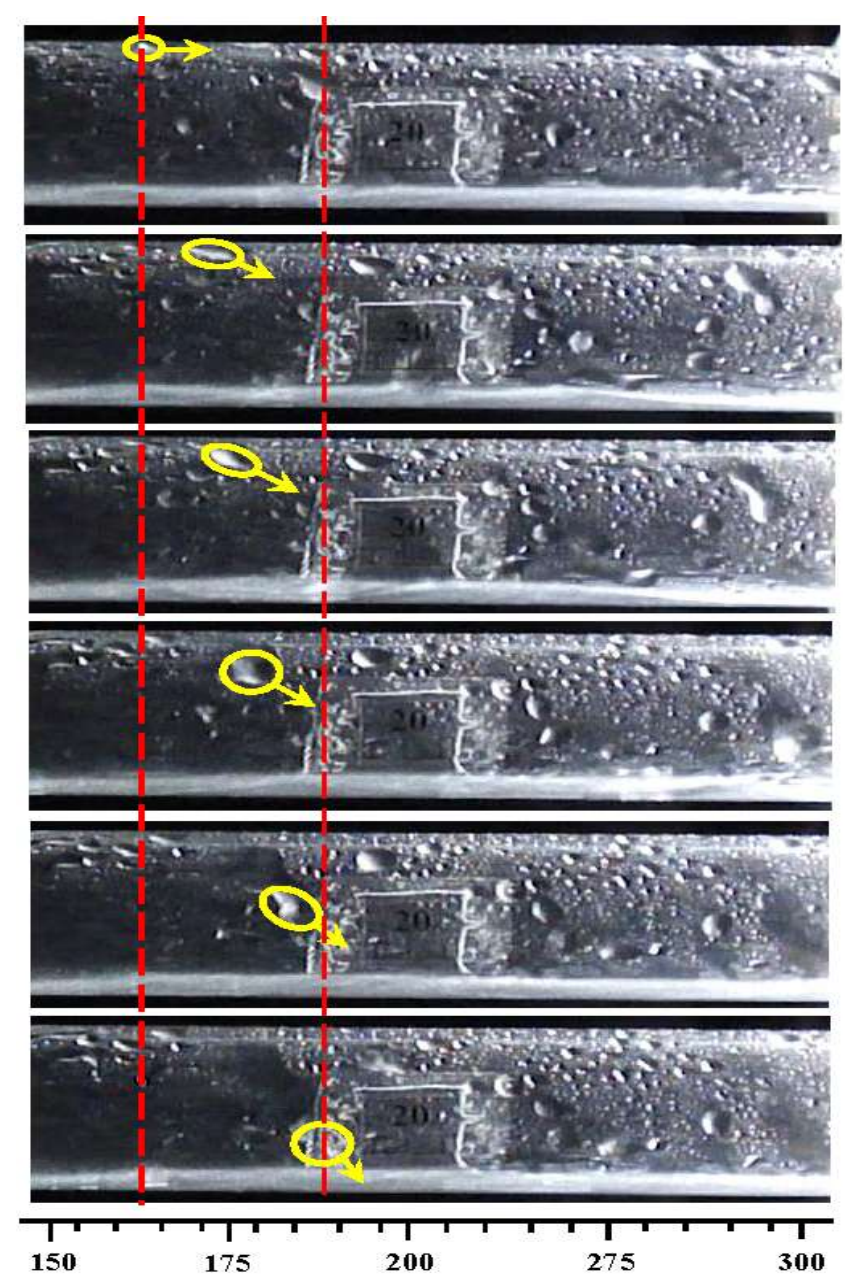

Figure 10. Sequential frames to illustrate liquid droplet movement from top to bottom of the pipe between $150 \mathrm{~mm}$ and $300 \mathrm{~mm}$ from the inlet ( $\dot{m}=13.1 \mathrm{~g} / \mathrm{s}$ and $\mathrm{x}=5.4 \%$, flow direction from left to right) 


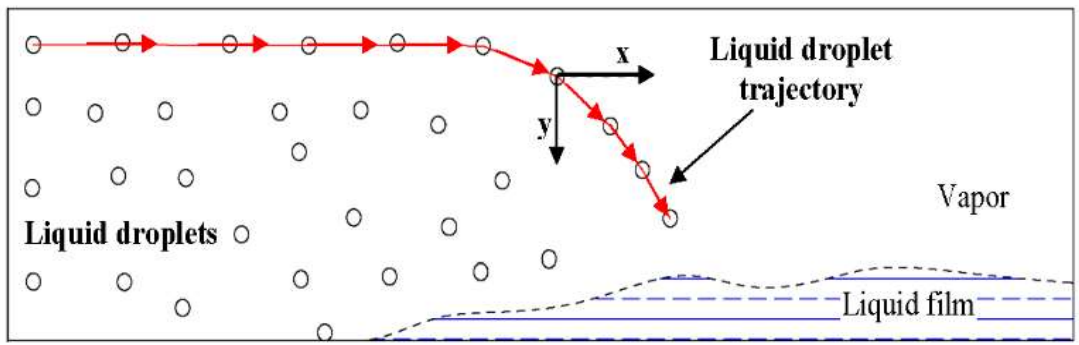

Figure 11. Sketch for droplet trajectory during the movement from the top to the bottom of the pipe

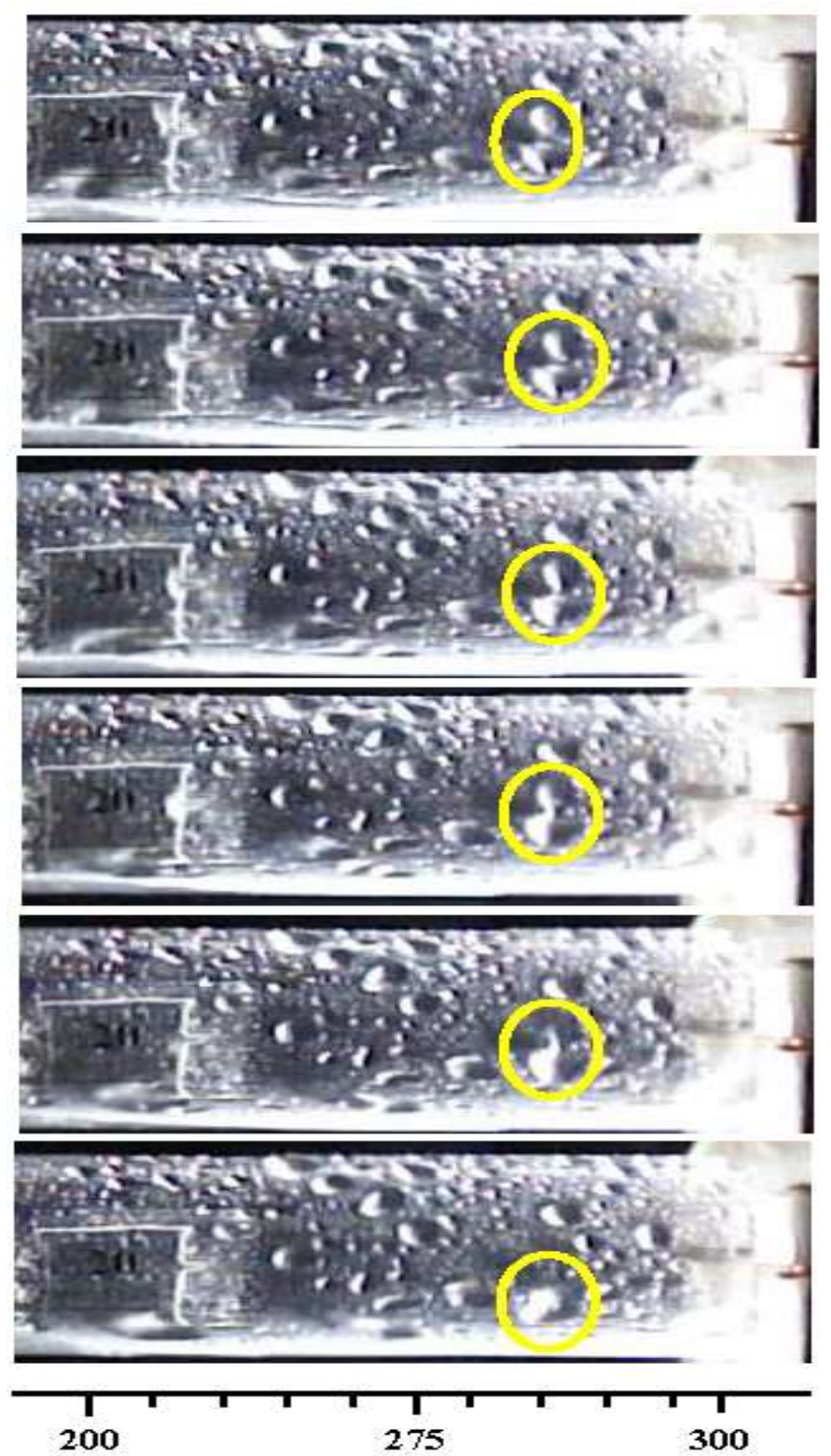

Figure 12. Sequential frames to illustrate the observed liquid droplets merging between $275 \mathrm{~mm}$ and $300 \mathrm{~mm}$ from the inlet, $\dot{m}=10.2 \mathrm{~g} / \mathrm{s}$ and x $=5.4 \%$, flow direction from left to right 


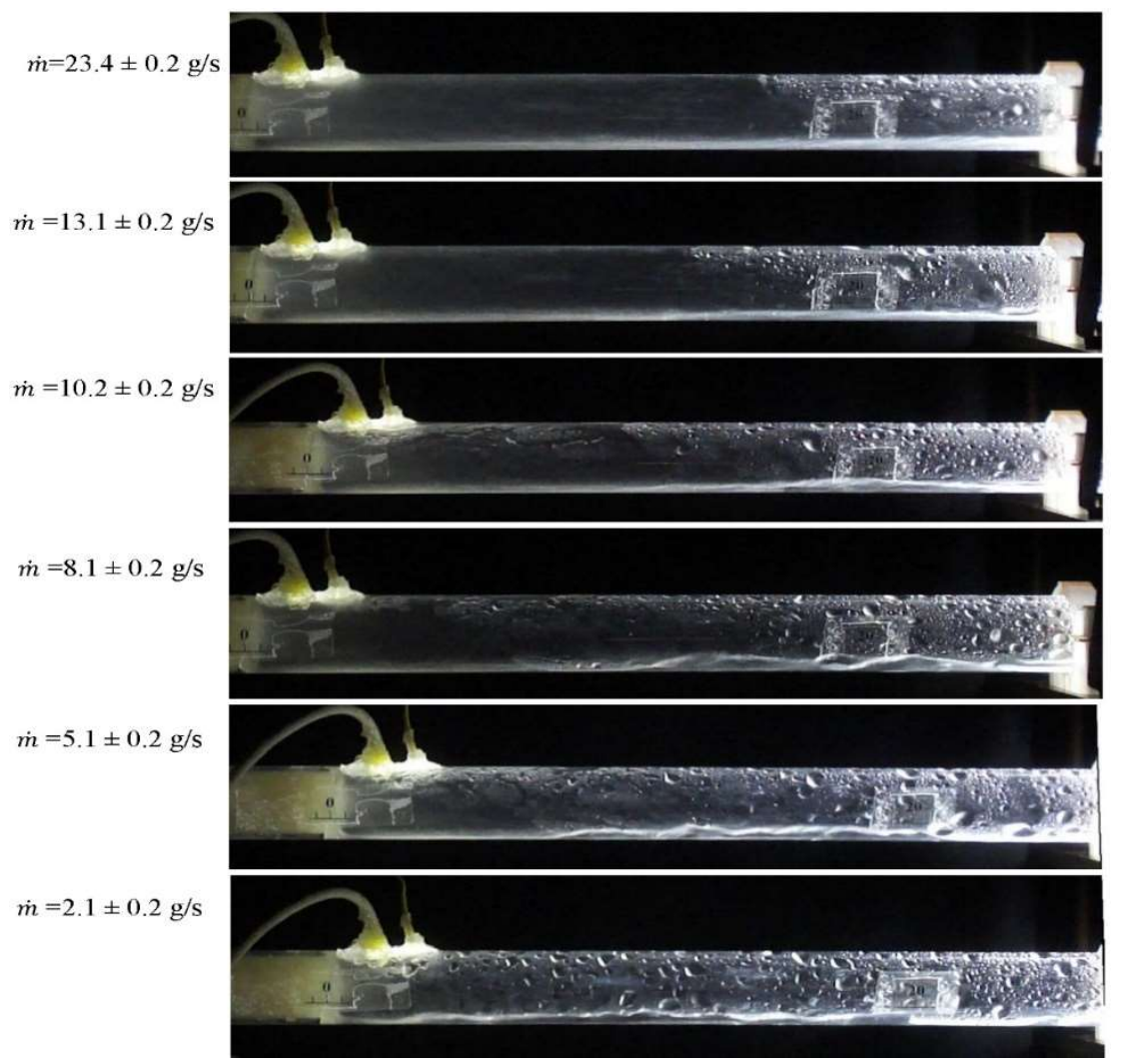

Figure 13. Images of two-phase flow at different mass flow rate directly after the expansion device at the upstream end of the pipe. Images extend from $0 \mathrm{~mm}$ to $300 \mathrm{~mm}$ from the inlet, flow direction from left to right

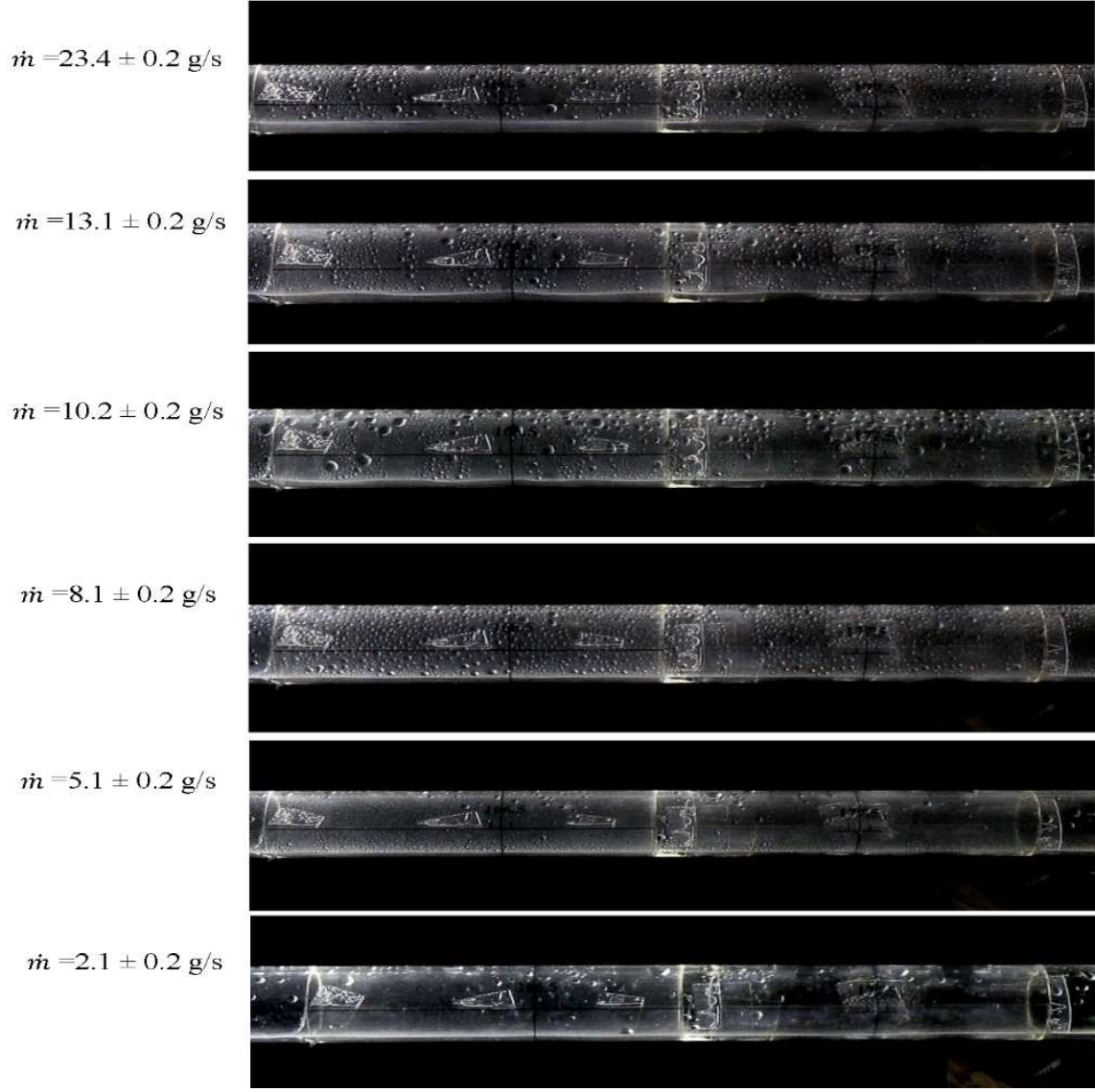

Figure 14. Images of two-phase flow at different mass flow rate at the downstream end of the pipe. Images extend from $1500 \mathrm{~mm}$ to $1800 \mathrm{~mm}$ from the inlet, flow direction from left to right 


\section{Expansion length at the bottom}

A criteria for definition the expansion length at the bottom has been used by Hrnjak [3], Fei [20] and Bowers [17]; the criteria is the clear formation of a liquid film at the bottom of the pipe. In this study, the liquid film formation is observed at the bottom of the pipe for all the operating conditions. Figure 15 illustrates identification of the start of the liquid film from one of the operating conditions.

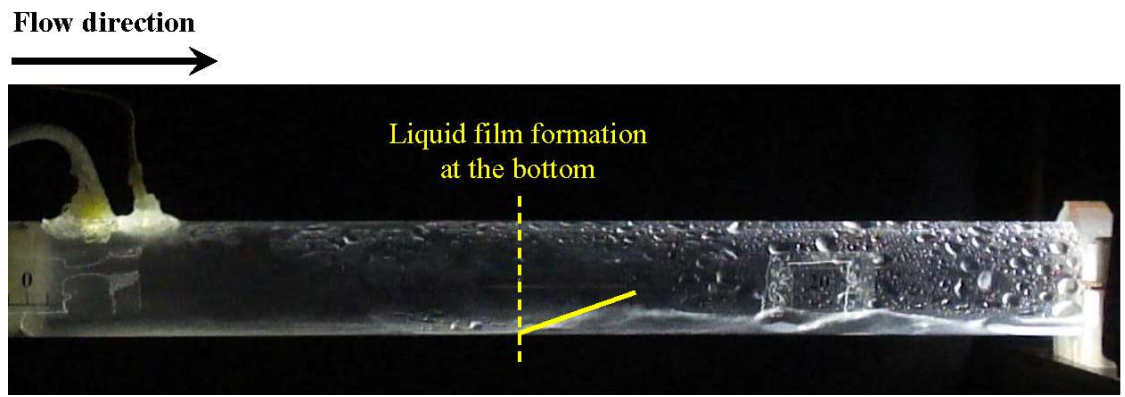

Figure 15. Images showing liquid film formation at the bottom of the pipe at locations from $0 \mathrm{~mm}$ to $300 \mathrm{~mm}$ from the inlet, $\dot{m}=8.1 \mathrm{~g} / \mathrm{s}$ and $\mathrm{x}=5.5 \%$

Figure 16 presents the expansion length according to the liquid formation at the bottom of the pipe. The location of the detectable start of the liquid film at the bottom of the pipe also changes with time. Hence there are uncertainties in the application of the expansion length criteria. Error bars denote the estimated experimental uncertainty in defining the distance from the experimental data. The mass velocity has a significant effect on the expansion length. The expansion length increases as a result of higher initial velocity.

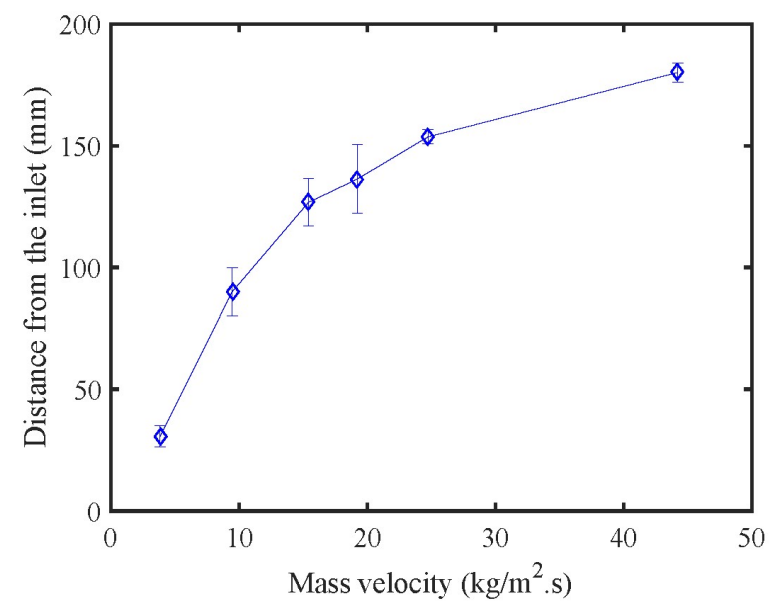

Figure 16. Length of the expansion region from the inlet of tube based on the liquid formation at the bottom of the pipe

\section{CFD Simulation Results}

Two-phase flow development on the bottom of the pipe

In order to show the simulated two-phase flow development after the expansion device, contours of the liquid volume fraction were plotted along the axial vertical plane from the inlet of the tube as illustrated in Figure 17 for the case of $\dot{m}=23.4 \mathrm{~g} / \mathrm{s}$. The red area represents the liquid film at the bottom of the pipe and the transitional colors between the red and blue represents the interface between the phases. volume fraction distribution on three cross-section planes at distances of $5 \mathrm{~cm}, 10 \mathrm{~cm}$ and $20 \mathrm{~cm}$ from the inlet are also shown in Figure 16 When the volume fraction of the liquid is equal to 1, the two-phase flow is completely single phase in liquid state and when the two-phase flow becomes completely single phase vapour, the liquid volume fraction is equal to zero.

The cross-section contours on the plane at $20 \mathrm{~cm}$ Figure 16 (d) illustrate the flow in the fully developed region as the liquid height remains the same at stations further downstream and there is no significant change after this plane. The differences in the liquid volume fraction distribution between the planes at $5 \mathrm{~cm}, 10 \mathrm{~cm}$, and 20 $\mathrm{cm}$ Figure 16 (b), (c), and (d) also demonstrates that the flow is developing within this region. Contours of the simulated liquid volume fraction at the different operating conditions are presented in Figure 18. 


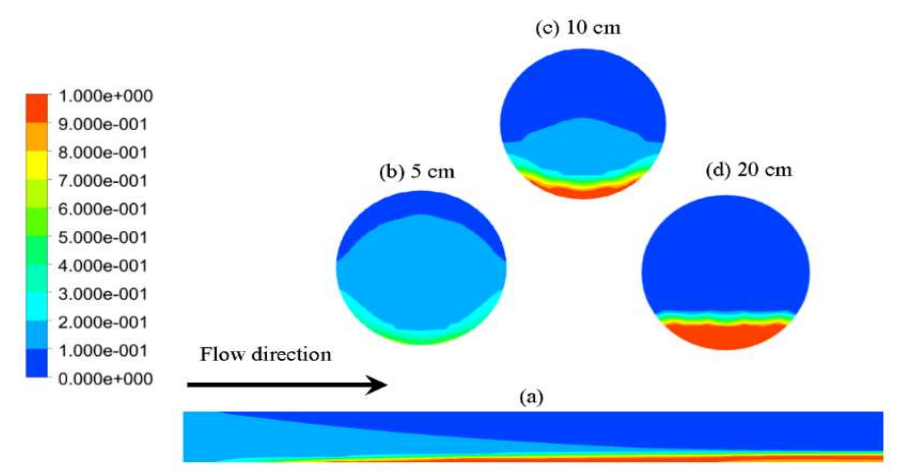

Figure 17. Liquid volume fraction (LVF) for $\dot{m}=23.4 \mathrm{~g} / \mathrm{s}$ (a) LVF along the axial vertical plane; (b) LVF at $5 \mathrm{~cm}$ from the inlet; (c) LVF at $10 \mathrm{~cm}$ from the inlet; and (d) LVF at $20 \mathrm{~cm}$ from the inlet

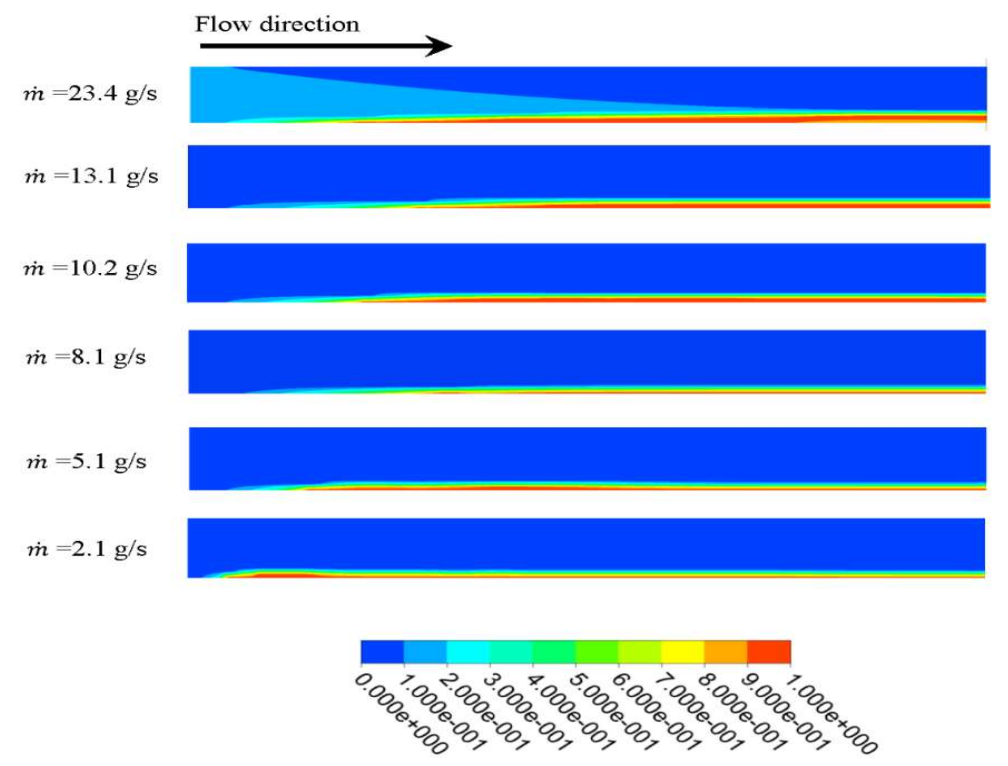

Figure 18. Liquid volume fraction along the axial vertical plane at the different operating conditions

To compare the simulated results for the length of the developing region with the data from experiments, a method is needed for quantifying the simulated position where the initiation of liquid film development occurs. Liquid volume fraction results are shown in Figure 19 for $\dot{m}=5.1 \mathrm{~g} / \mathrm{s}$. In order to specify the location of the start of the liquid film, Figure 20 presents contour lines, and a zoomed-in view showing the starting point of the liquid layer formation is presented in Figure 21.
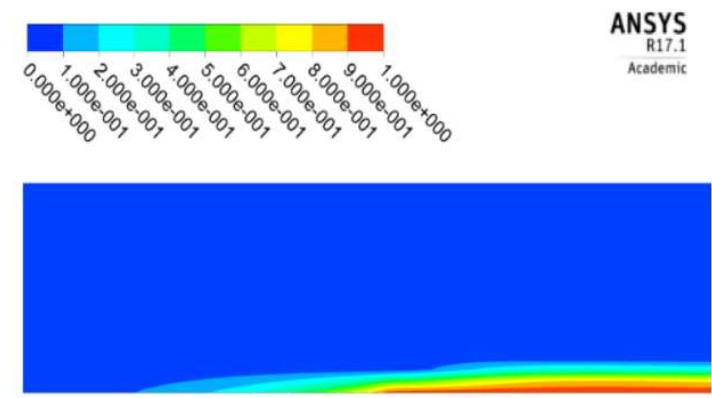

$\stackrel{\text { Flow direction }}{\longrightarrow}$

Figure 19. Contours of liquid volume fraction showing liquid formation at the bottom of the pipe on the axial vertical plane for $\dot{m}=5.1 \mathrm{~g} / \mathrm{s}$ 


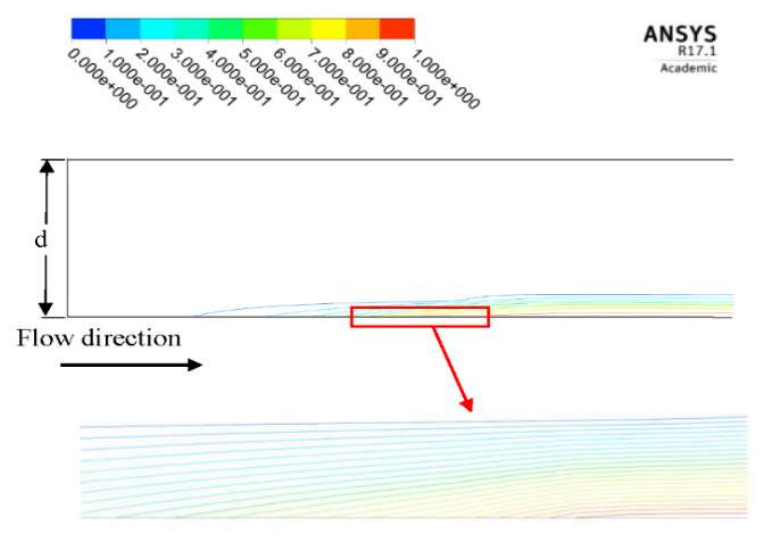

Figure 20. Contours line of liquid volume fraction showing liquid formation at the bottom of the pipe on the axial vertical plane for $\dot{m}=5.1$

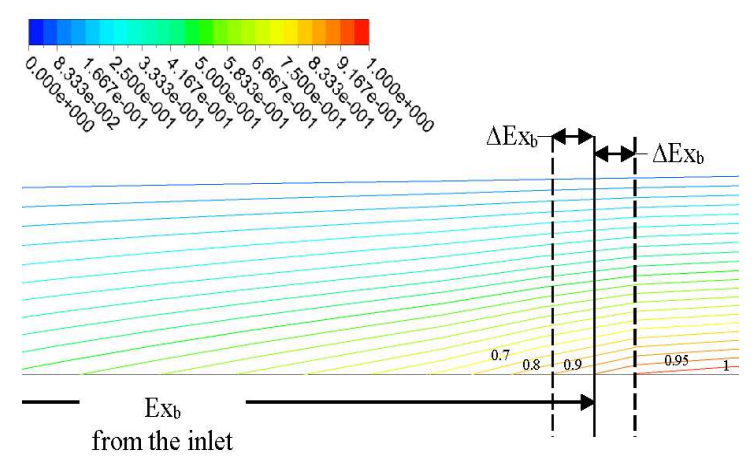

Figure 21. Zoomed-in view of contours line of liquid volume fraction showing liquid formation at the bottom of the pipe on the axial vertical plane for $\dot{m}=5.1 \mathrm{~g} / \mathrm{s}$

The simulated expansion length at the bottom of the pipe $\mathrm{Ex}_{\mathrm{b}}$ is defined as the distance from the inlet to the location where the LVF $=0.95$ on the lower-most wall of the pipe. For the case of $\dot{m}=5.1 \mathrm{~g} / \mathrm{s}$ illustrated in Figure 20, $E x_{b}=82.7 \mathrm{~mm}$. A value for the LVF of 0.95 was chosen in preference to the value of 1.00 because a value of unity might be approached asymptotically in some simulations, potentially leading to unrealistically long expansion length values. The quantity $\Delta \mathrm{Ex}_{\mathrm{b}}$ shown on Figure 20 is defined as the distance between LVF contours of 0.90 and 0.95 and is presented as an indicator of the uncertainty associated with defining the expansion length in the simulations.

The experimental data and simulations are compared in Figure 22. The simulations underestimate the expansion length and the mean difference between the experimental data and the numerical results is $8 \%$. The uncertainty in defining the expansion length from the simulations vary from $\Delta \mathrm{Ex}_{\mathrm{b}}=0.9 \mathrm{~mm}$ in the lowest mass flow rate case up to $\Delta \mathrm{Ex}_{\mathrm{b}}=2.1 \mathrm{~mm}$ in the highest mass flow rate case. Therefore, this uncertainty is very small relative to those associated with the data from the experiments.

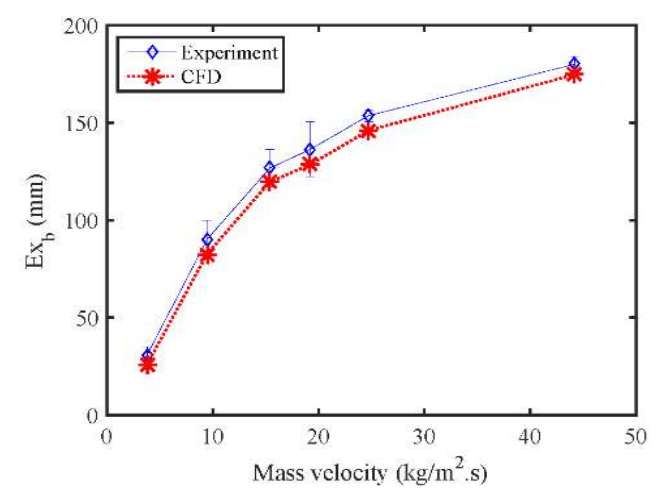

Figure 22. Comparison between the experimental data and numerical simulation for the expansion length at the bottom of the pipe 


\section{Liquid height in developed region}

In order to determine the liquid height according to the liquid volume fraction definition and compare it with the experimental data, transverse vertical plane at $1665 \mathrm{~mm}$ from the inlet is defined in the CFD simulations. Figure 23 illustrates the liquid volume fraction distribution at this location and includes the liquid height definition which is illustrated by the distance between the two vertical lines. The liquid height is defined by the zone in which the liquid volume fraction is greater than 0.95 , an approach consistent with that adopted for the expansion region. The simulated liquid volume fraction in the fully developed region for the different operating conditions is shown in Figure 24. It is seen that the mass flow rate has a significant effect on the liquid height. The experimental results are also included in Figure 25 and it is observed that the experiments and numerical simulations have same trend, although the difference between the experimental and numerical results is about 8 $\%$.

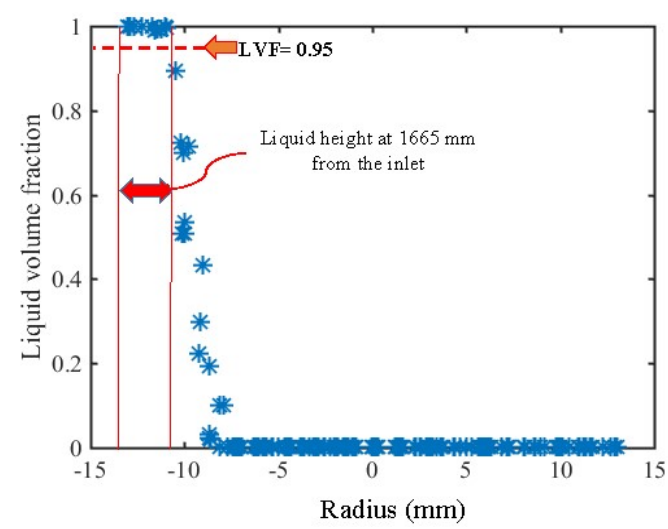

Figure 23. Liquid height identification on the central vertical plane of the pipe at $1665 \mathrm{~mm}$ from the inlet, according to the liquid volume fraction definition for $\dot{m}=13.1 \mathrm{~g} / \mathrm{s}$
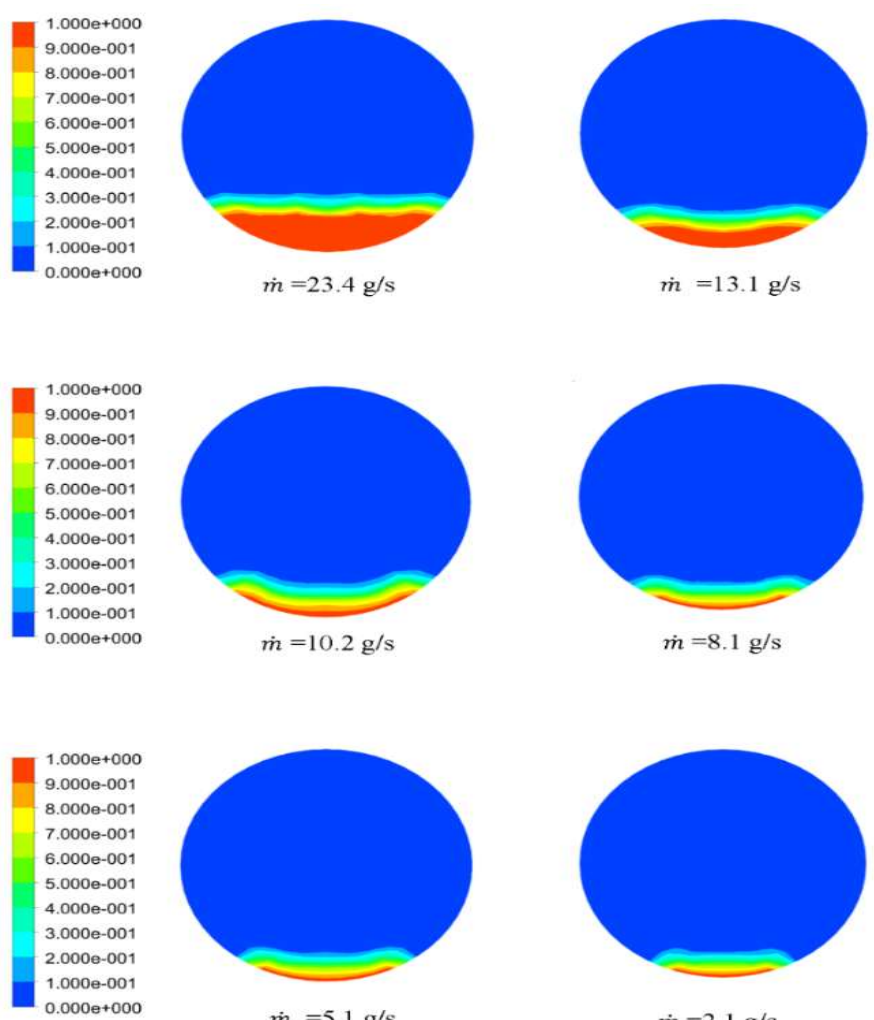

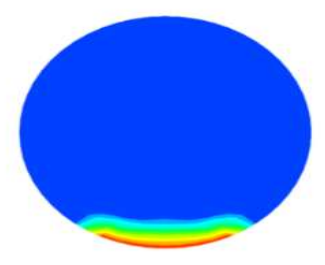

$\dot{m}=5.1 \mathrm{~g} / \mathrm{s}$

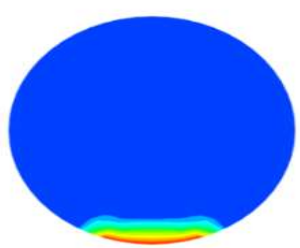

$\dot{m}=2.1 \mathrm{~g} / \mathrm{s}$

Figure 24. Liquid volume fraction on the vertical planes perpendicular to the flow direction at $1665 \mathrm{~mm}$ from the inlet for the different operation conditions 


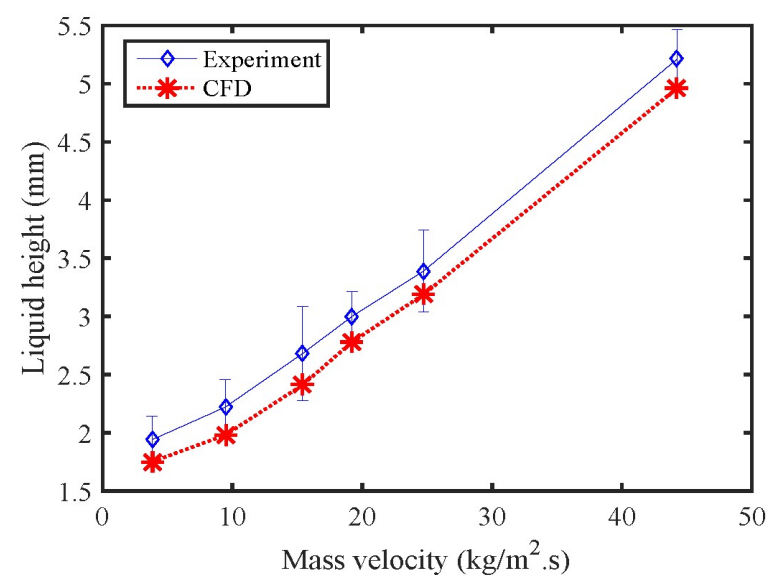

Figure 25. Comparison between the experimental data and numerical simulations for the liquid height on the central vertical plane of the pipe at $1665 \mathrm{~mm}$ from the inlet

\section{CONCLUSION}

In this study, the two-phase flow development after an expansion device has been investigated and experimentally observed. An experimental apparatus was designed and built to provide operating conditions for the two-phase flow development after the expansion device. The CFD was used to simulate and assess the twophase flow. The results obtained in this study may provide real data base for the water two-phase flow and CFD simulations. The main results can be summarized as follows.

1- The two-phase flow develops gradually after the expansion device. The expansion length was less than 200 $\mathrm{mm}$ for all conditions tested.

2- Increase the mass flow rate has a direct, and significant effect on the expansion length.

3- An increase of the mass flow rate causes an increase in the void fraction and a reduction in the slip ratio in the developed region.

4- A fully developed stratified flow pattern was observed in all the experiments within the pipe length.

5- Comparison of the experimental data and simulations indicate, the simulations underestimate the expansion length and fully developed liquid film height by about $8 \%$.

7- The distance to the fully developed region was identified from the CFD simulation result. Therefore, the required length of the inlet pipe of the vertical flash tank separator can be selected.

\section{NOMENCLATURE}

A Area, $\mathrm{m}^{2}$

CFD Computational fluid dynamic

D Tube diameter, $\mathrm{mm}$

$d m \quad$ Droplet diameter, micron

Ex Expansion region length, $\mathrm{mm}$

$F_{q} \quad$ External body force, $\mathrm{N}$

$F_{\text {lift }, q} \quad$ Lift force, $\mathrm{N}$

$F_{v m, q} \quad$ Virtual mass force, $\mathrm{N}$

$G \quad$ Mass flux, $\mathrm{kg} / \mathrm{m}^{2} . \mathrm{s}$

$g \quad$ Gravity, $\mathrm{m} / \mathrm{s}^{2}$

$K_{p q} \quad$ Inter-phase momentum coefficient.

LVF Liquid volume fraction

$m_{p q} \quad$ Mass transfer from phase $\mathrm{p}$ to phase $\mathrm{q}, \mathrm{kg} / \mathrm{s}$

$m_{q p} \quad$ Mass transfer from phase $\mathrm{q}$ to phase $\mathrm{p}, \mathrm{kg} / \mathrm{s}$

$\mathrm{Q}_{\mathrm{t}} \quad$ Total volume flow rate, $\mathrm{m}^{3} / \mathrm{s}$

$\mathrm{Q}_{\mathrm{q}} \quad$ Volume flow rate for phase $\mathrm{q}, \mathrm{m}^{3} / \mathrm{s}$

$R_{p q} \quad$ Interaction force between phases, $\mathrm{N}$

$S_{q} \quad$ Source term which can be specified as constant or user defined mass source for each phase 


$\begin{array}{ll}U_{q}, U_{l} & \text { Phase weighted velocities, } \mathrm{m} / \mathrm{s} \\ \mathrm{u}_{\mathrm{g}} & \text { Local vapour velocity, } \mathrm{m} / \mathrm{s} \\ \mathrm{u}_{1} & \text { Local liquid velocity, } \mathrm{m} / \mathrm{s} \\ v_{q} & \text { Velocity of phase } \mathrm{q}, \mathrm{m} / \mathrm{s} \\ x & \text { Vapour quality }\end{array}$

Greek symbols

$\begin{array}{ll}\alpha & \text { Phase volume fraction. } \\ \mu_{g} & \text { Vapour dynamic viscosity, } \mathrm{kg} / \mathrm{m} . \mathrm{s} \\ \mu_{l} & \text { Liquid dynamic viscosity, } \mathrm{kg} / \mathrm{m} . \mathrm{s} \\ \rho_{g} & \text { Vapour density, } \mathrm{kg} / \mathrm{m}^{3} \\ \rho_{l} & \text { Liquid density, } \mathrm{kg} / \mathrm{m}^{3} \\ \tau_{q} & \text { Stress-strain tensor of } q \text { phase } \\ \lambda_{q} & \text { Shear of phase } q, \mathrm{~N} / \mathrm{m}^{2} \\ \sigma_{q} & \text { Surface tension of phase } \mathrm{q}, \mathrm{kg} / \mathrm{s}^{2}\end{array}$

\section{REFERENCES}

[1] Srisomba R, Mahian O, Dalkilic AS, Wongwises S. Measurement of the void fraction of R-134a flowing through a horizontal tube, International Communications in Heat and Mass Transfer. 2014;56:8-14. doi: 10.1016/j.icheatmasstransfer.2014.04.004.

[2] Chen H, Xu J, Li Z, Xing F, Xie J. Stratified two-phase flow pattern modulation in a horizontal tube by the mesh pore cylinder surface, Applied Energy. 2013;112(0):1283-90. doi: 10.1016/j.apenergy.2012.11.062.

[3] Hrnjak P. Developing Adiabatic Two-Phase Flow in Headers-Distribution Issue in Parallel Flow Microchannel Heat Exchangers, Heat transfer engineering. 2004; 25(3): 61-68. doi: 10.1080/01457630490280128.

[4] Awwad A, Xin RC, Dong ZF, Ebadian MA, Soliman HM. Measurement and correlation of the pressure drop in air-water two-phase flow in horizontal helicoidal pipes, International Journal of Multiphase Flow. 1995;21(4):607-19.. doi: 10.1016/0301-9322(95)00011-L.

[5] Canière H, T'Joen C, Willockx A, De Paepe M, Christians M, Van Rooyen E, Liebenberg L, Meyer JP. Horizontal two-phase flow characterization for small diameter tubes with a capacitance sensor, Measurement Science and Technology. 2007;18(9):2898. doi:10.1088/0957-0233/18/9/020.

[6] Bhramara P, Rao VD, Sharma KV, Reddy TKK. CFD Analysis of Two-Phase Flow in a Horizontal PipePrediction of Pressure Drop, Proceedings of World Academy of Science: Engineering \& Technology. 2008; 42.

[7] Dalkilic A, Agra O, Teke I, Wongwises S. Comparison of frictional pressure drop models during annular flow condensation of R600a in a horizontal tube at low mass flux and of R134a in a vertical tube at high mass flux, International Journal of Heat and Mass Transfer. 2010;53(9):2052-2064. doi:10.1016/j. ijheatmasstransfer.2009.12.051

[8] Ekambara K, Sean Sanders R, Nandakumar K, Masliyah JH. CFD Modeling of Gas-Liquid Bubbly Flow in Horizontal Pipes: Influence of Bubble Coalescence and Breakup, International Journal of Chemical Engineering. 2012;2012:20. doi: 10.1155/2012/620463.

[9] Kondou C, Hrnjak P. Condensation from superheated vapor flow of R744 and R410A at subcritical pressures in a horizontal smooth tube, International Journal of Heat and Mass Transfer. 2012;55(1112):2779-91. doi: 10.1016/j.ijheatmasstransfer.2012.01.030.

[10] Dasari A, Desambala AB, Dasmahapatra AK, Mandal TK. Experimental studies and PNN prediction on flow pattern of viscous oil-water flow through a circular horizontal pipe, Industrial \& Engineering Chemistry Research, 2013. doi: 10.1021/ie301430m.

[11] Becker A, Kapitz M, aus der Wiesche S. Numerical Simulation of Single Bubble Dynamics During Flow Boiling Conditions on a Horizontal Surface, Heat transfer engineering. 2014;35(5):461-71. doi: 10.1080/01457632.2013.833045.

[12] Bottin M, Berlandis JP, Hervieu E, Lance M Marchand M, Ozturk OC, Serre G. Experimental investigation of a developing two-phase bubbly flow in horizontal pipe, International Journal of Multiphase Flow. 2014;60(0):161-79. doi: 10.1016/j.ijmultiphaseflow.2013.12.010. 
[13] Rana KB, Agrawal GD, Mathur J, Puli U. Measurement of void fraction in flow boiling of ZnO-water nanofluids using image processing technique, Nuclear Engineering and Design. 2014;270(0):217-26. doi: 10.1016/j.nucengdes.2014.01.008.

[14] Duan J, Gong J Yao H, Deng T, Zhou J. Numerical modeling for stratified gas-liquid flow and heat transfer in pipeline, Applied Energy. 2014;115:83-94.. doi: 10.1016/j.apenergy.2013.10.050.

[15] Tong R. CFD simulation of separation of two-phase flows systems in Mechanic Automation and Control Engineering (MACE), Second International Conference;2011. IEEE. doi:10.1109/MACE.2011.5987125

[16] Shoukri M, Hassan I, Peng F. Steam-water stratified flow in T-junctions - Experiments and modelling, Transactions of The Canadian Society for Mechanical Engineering. 2002;26(2):241-59. doi: 10.1139/tcsme-2002-0014.

[17] Bowers CD. Developing Adiabatic Two-Phase Flow: ProQuest, 2009.

[18] Zhao Y, Chen G, Ye C, Yuan Q. Gas-liquid two-phase flow in microchannel at elevated pressure, Chemical engineering science. 2013;87(0):122-32. doi: 10.1016/j.ces.2012.10.011.

[19] Bowers CD, Hrnjak PS. Using change point analysis for image processing of developing adiabatic twophase flow after expansion valve. in ASME/JSME 2007 5th Joint Fluids Engineering Conference; 2007. American Society of Mechanical Engineers. doi: 10.1115/FEDSM2007-37633.

[20] Fei P. Adiabatic Developing Two-phase Refrigerant Flow in Manifolds of Heat Exchangers. University of Illinois at Urbana-Champaign; 2004.

[21] Cheng L, Ribatski G, Quibèn JM, Thome JR. New prediction methods for CO2 evaporation inside tubes: Part I - A two-phase flow pattern map and a flow pattern based phenomenological model for two-phase flow frictional pressure drops, International Journal of Heat and Mass Transfer. 2008;51(1-2):111-24. doi: 10.1016/j.ijheatmasstransfer.2007.04.002.

[22] Roman AJ, Kraitzer PJ, Ervin JS, Hanchak MS, Byrd LW. Flow pattern identification of horizontal twophase refrigerant flow using neural networks, International Communications in Heat and Mass Transfer. 2016;71:254-64. doi: 10.1016/j.icheatmasstransfer.2015.12.033.

[23] Roul MK, Sahoo LK. CFD modeling of pressure drop caused by two-phase flow of oil/water emulsions through sudden expansions, International Journal of Engineering Research and Application. 2012;2(6):1047-54.

[24] Walvekar RG, Choong TSY, Hussain SA, Khalid M, Chuah TG. Numerical study of dispersed oil-water turbulent flow in horizontal tube, Journal of Petroleum Science and Engineering. 2009;65(3):123-8. doi:10.1016/j.petrol.2008.12.019.

[25] FLUENT, A., 14.5, Theory Guide; ANSYS. Inc., Canonsburg, PA, 2012.

[26] Desamala AB, Dasari A, Vijayan V, Goshika BK, Dasmahapatra AK, Mandal TK. CFD Simulation and Validation of Flow Pattern Transition Boundaries during Moderately Viscous Oil-Water Two-Phase Flow through Horizontal Pipeline, International Journal of Chemical, Material Science and Engineering. 2013;7(1):1150.

[27] Kerdouss F, Bannari A, Proulx P. CFD modeling of gas dispersion and bubble size in a double turbine stirred tank, Chemical Engineering Science. 2006;61(10):3313-22. doi: 10.1016/j.ces.2005.11.061.

[28] El Hajal J, Thome JR, Cavallini A. Condensation in horizontal tubes, part 1: two-phase flow pattern map, International Journal of Heat and Mass Transfer. 2003;46(18):3349-63.

[29] Mahmood RA. Experimental and computational investigation of gravity separation in a vertical flash tank separator in Faculty of Health, Engineering and Sciences - School of Mechanical and Electrical Engineering, University of Southern Queensland; 2018.

[30] Mahmood RA, Buttsworth D, Malpress R. Computational and Experimental Investigation of the Vertical Flash Tank Separator Part 1: Effect of Parameters on Separation Efficiency, International Journal of AirConditioning and Refrigeration. 2019;27(1). doi: 10.1142/S2010132519500056.

[31] Mahmood RA, Buttsworth D, Malpress R. Computational and Experimental Investigation of using an Extractor in the Vertical Gravitational Flash Tank Separator, International Journal of Automotive and Mechanical Engineering. 2019;16(2):6706-22.

[32] Parkash O. Flow characterization of multi-phase particulate slurry in thermal power using computational fluid dynamics, Journal of Thermal Engineering. 2020;6(1):187-203. 